\section{Clinical bepartment.}

TWO CASES OF SPASMODIC TORTICOLLIS: ONE CURED, THE OTHER MUCH RELIEVED BY MECHANICAL TREATMENT.

BY IIERBERT J. HALL, M.D., MARBLEHEAD, MASS.

Case I. Miss R., age thirty-eight, dressmaker.

Family and previous histories negative except that when the patient was about twenty years old sbe is said to have had a number of "falling fits." For a year previous to the attack of torticollis she worked very steadily at the sewing-machine. In July, 1896, she first noticed slight stiffness and an occasional twitch in the muscles of the neck. The spasm soon became marked and grew worse co fast that in two weeks she was obliged to give up all work. She was treated for a while by a physician who tried sedatives without effect.

December 2, 1896. On this date, a little over five months from the time of the onset, the patient was first seen by the writer. She had been in bed several days, unable to sit in a chair or to walk about without extreme annoyance from the spasm. In recumbency there were no unnatural movements of the head, but immediately on sitting up would begin a series of rhy thmic contractions of the sterno-mastoid on the right and all the posterior rotators and retractors on the left.

The head was turned with much force to the left, and was markedly retracted. 'The deviation from the normal would sometimes terminate with the face looking directly upward, and the chin twisted as far round as the left shoulder. It was observed during the examination that a firm grasp of the hand on the nape of the neck would greatly diminish the force of the spasm.

December $7 \mathrm{th}$. The spasm was at once decreased, and is now nearly controlled by the application of a spring clamp to the back and sides of the neck. The clamp is very simple in construction and does practically what the thumb and fingers do in grasping the neck from behind. It is made of light spring steel, broader than, but otherwise similar to, the ordinary trouser-guards worn by bicyclists. There is a tailpiece running from the middle of the spring about six inches down the back. When the clothing is buttoned tightly over it, this tail-piece helps to keep the spring closely applied. A gentle pressure was thus exerted on the back and sides of the neck as far forward as the anterior borders of the sterno-mastoids. The results were best when the collar was worn at about the level of the angle of the jaw. The application of this simple apparatus instantly stopped most of the twitching, although the symptoms would at once recur upon removal of the pressure.

January 1, 1897. The apparatus has been worn constantly, but it can now be discarded for several hours a day without recurrence of the spasm. There is still some rigidity and a slight tendency to clonic spasm in the affected muscles.

February 3d. On account of his interest in these cases, the patient was sent to Dr. George L. Walton, for observation and prognosis. Dr. Walton referred the case to Dr. F. I. Proctor, who later reported astigmatism and obliquity of the axis of vision in both eyes. Glasses prescribed.

1 Read in part at the March meeting of the Essex South Division of the Massachusetts Medical Society, and presented by title at the May
January 20, 1898. Neither clamp nor glasses bave been worn for several months. Patient does a little sewing and attends to ordinary household duties without inconvenience. She has taken several long walks. There is a slight left torticollis of a fixed and painless vature due to a permanent contraction of the affected muscles. She turns her head freely in any direction. There is no retraction.

\section{SUMIIARY OF CASE I.}

A severe spasmodic torticollis of five months' stand. ing was at once relieved and has remained under control for two years by the simple expedient of spring pressure on the cervical muscles. For several weeks the spasm recurred on removal of the apparatus, but later no appliance was necessary. The affection was brought under control in spite of the existence of marked ocular defect. No drugs, no exercises, no massage or electricity, no complicated fixation apparatus were used in bringing about the desired result.

CASE II. Miss F., age thirty-two, shoe-shop hand. Referred by Dr. Herbert W. Newhall, of Lynn. Family history, negative. Previous history, always reasonably well until present attack. Duration of symptoms five weeks. Gradual onset without pain. The patient has worked for five or six years in a shoeshop, doing always the same work, which requires the constant use of a light hammer, pounding on the leather.

February 29, 1898. Physical examination showed a young woman of medium height and rather slight build. Nothing abnormal was observed except the severe spasin which kept in constant action the right sterno-mastoid and the left posterior cervical rotators. The motions of the head in this case were very similar to those observed in the preceding case, but they could not be so easily controlled by the hand. A reasonabiy good prognosis was given, however, and measurements were taken for a spring collar.

March 6th. The clawp has been worn one week and there is plainly an improvement, although the spasm is still severe.

'Ireatment continued and supplemented by a series of I)elsarte movements designed to limber up all joints, and to bring about a relaxation of all the muscles of the body and especially of the muscles of the neck. Strangely enough the exercise which seemed to relax the neck most is one in which the hauds are shaken violently and loosely on the relaxed wrists.

March 30tb. 'The head can now be held straight for a brief space of time and the existing spasm is less severe. A Thomas's collar stuffed with oakum has been substituted for the clamp which, though padded and covered with chamois-skin, has caused chafing.

April 12th. There has been very decided improvement remarked by every one who sees the patient. The twitching, although it does not carry the head so far or so forcibly, is still annoying and various forms of head support have been tried without relief. The patient herself decides to go back to the collar as being of the greatest service. The patient's day has been plotted out carefully into periods of rest and exercise. New exercises have been introduced which tend to develop the entire body. She can now voluntarily relax the tense sterno-mastoid. The eyes have been examined by Dr. Cobb, of Lynn, who finds in this case also astigmatism and oblique visual axis.

May 1st. The spasmodic motions have almost 
wholly ceased. Neither glasses nor collar are worn constantly. She cannot turn ber head beyond the middle line to the right, but it can be held very nearly front without difficulty. A slight tovic contraction of the right sterno-mastoid turns the head persistently a little to the left; there is no retraction. Much walking or over-exercise of any kind causes pain in the left shoulder. The patient has not from the first been allowed to use her eyes for reading or sewing. To-day she adonits that she has read a short story, but without relapse.

May 30th. Slight improvement from last note. The patient is very cheerful, aud expects to be able to turn her head freely in any direction before long.

\section{SUMMARY OF CASE II.}

A severe case of spasmodic torticollis of five weeks' duration, somewhat relieved at once and in three months practically cured by the spring clamp supplemented by a careful system of gymnastics designed to relax as well as to develop all muscles, and especially those of the neck. Very little attention was given to the development of the muscles directly opposed to those involved in the spasm. The exercises were designed to improve the general poise and to secure good muscular control throughout the body.

\section{GENERAL CONSIDERATIONS.}

The experience of the men in this vicinity in dealing with this disease has been rather unsatisfactory. Some cases have been passed along from general practitioner to orthopedist, to neurologist, to masseur, to ophthalmologist aud finally to the general surgeon, all this perhaps without improvement.

When all other means fail the general surgeon stands ready to do neurectomy on the spinal accessory and the posterior cervical branches. Even then, with all the posterior rotators and the sterno-mastoid divided, the twitching may not cease. This most persistent and annoying spasm is not accompanied by any structural changes either in the nerve trunks, or in the nerve centres.2 It seems therefore to some extent psychic or wental. ${ }^{3}$

Referring presumably to complete fixation, Richardson and Walton state that "Mechanical support to the head has proved not only inetficacious but unendurable, the restraint only adding to the discomfort aud tendency to iucrease spasm." 4 'They also refer to a case temporarily benefited by massage. Drugs, electricits and verve stretching have proved of no value.

It is certain that some cases must come to operation; nothing else will put a stop to this misguided activity, which though usually painless is so fatiguing and annoying that the patient gladly welcomes the most severe surgical measures.

The operation as practised by Dr. M. H. Richardson is very complete. 'The results in the cases which Dr. Richardson and Dr. Walton bave seen, are certainly excellent, although a second, or even a third operation has sometimes proved necessary, as the spasm is transferred to new sets of muscles. It is this rapid transferrence, for instance, from the sternomastoid to the posterior rotators of the opposite side which is the worst objection to operation.

2.Gowers : Diseases of the Nervous System, vol. ii, page 669. 3 . Redad : Le Torticolis et son Traitement, page 119.

4 Richardsou and Walton: The Operative Treatment of Spasmodic Torticollis with Cases. American Journal of the Medical Sciences, January, 1895.
On the otber hand, mechanical support is capable of a wider field than mere fixation as by the plaster helmet or a rigid head support of any kind. Dr. A. ' $T$. Cabot has one case of cure by the plaster helmet, but for the most part such treatment is absolutely unbearable. The pain becomes severe and when the restraint is removed the spasm returns, so much increased as often to cause muscular strain of serious proportions. Supports of wire from the shoulders of such construction as to resist the spasm by means of stiff springs against the side of the bead, do some good but do not seem to have brought about permanent improvement. Why the simple spring clamp which the writer has used should succeed 80 well in these cases cannot be given a clear explanation. A study of the contractious of spasmodic torticollis in their resistance to various restraining forces has convinced the writer that very mild pressure applied properly at the back and sides of the neck by the hand or a simple clasp of metal will give better control of the motion of the head than will any method which disregards the neck and seeks to hold the head itself. This is easily verified by trying it on the voluntary motions of a normal neck. Besides this, the skull on account of its rounded surface is difficult to hold. Control by pressure on the neck allows a fair amount of freedom to the head, a factor which is apparently necessary to success. Probably there are cases which will not yield at all to such measures as these, but the results which this paper records are certainly encouraging and should lead to an extended trial of the methods suggested.

\section{Zeporty of Societieg.}

\section{MAINE MEDICAL ASSOCIATION.}

Forty-Sixth Annual Meeting, at Portland, June $1-3,1898$.

ThE meeting opened at 10 o'clock A. M., 'Thursday, June 1st, Dr. W. K. OAkes, of Auburn, the President, in the chair.

The meeting was noted throughout for the small amount of outside business, and the promptness with which the papers announced were presented and discussed. After the usual preliminary business and the reading of the report of the treasurer,

Dr. G. H. Cummings, of Portland, read a paper on UTERINE DISPLACEMENTS.

It favored operative measures rather than the usual unsatisfactory treatment by continued replacement and pessaries. In prolapsus, ventral fixation was objected to as offering probable interference with future labors, and amputation of the wedge-like cervix or Alexander's operation were urged as preferable.

Dr. John F. Thompson, of Portland, pointed out the fact that restoration of the fascia support from below helped many of these displacements more than operations upon the ligaments above. So far as a pessary supplied this support it did good. He favored any operation for retro-displacements which would furnish a posterior ligament to hold the uterus up and the cervix back. Dr. Cummings said be would not favor radical operations until other measures had been carefully tried. 